\title{
ANÁLISE MICROBIOLÓGICA E FÍSICO-QUÍMICA DE DOCE DE LEITE VENDIDO NO COMERCIO INFORMAL DE CURRAIS NOVOS/RN
}

\author{
Ramon Araújo Dos Santos \\ Grupo de Pesquisa Biotecnologia dos alimentos, Instituto Federal do Rio Grande do Norte, \\ Campus Currais Novos, Formando do Curso Técnico em Alimentos. \\ E-mail: ramon.araujo1604@gmail.com. \\ Regina Célia Pereira Marques \\ Grupo de Pesquisa Biotecnologia dos alimentos, Universidade do Estado do Rio Grande do \\ Norte, Campus Central, Dra em Microbiologia. E-mail: reginamarques@uern.br
}

\section{RESUMO}

O doce de leite é um importante alimento produzido e comercializado, principalmente, no Brasil e na Argentina, esse alimento apresenta elevado valor nutricional e é menos perecível que o leite e de grande aceitação sensorial. (DEMIATE et al., 2001).As DVAs (Doenças Veiculadas por Alimentos) são responsáveis, atualmente, pela maior parte dos surtos de diarréia em quase todos os países. Os alimentos artesanais têm maior possibilidade de se apresentarem contaminados pelo uso de matérias-primas de fontes não-seguras (DUARTE et al., 2005). A ANVISA estabelece por meio da Resolução RDC n ${ }^{\circ} 12$ de 02 de janeiro de 2001 que o doce de leite deve ser analisado quanto à presença dos principais enteropatógenos (ANVISA, 2001). O presente estudo teve por objetivo analisar, microbiologicamente amostras de doce de leite comercializadas na feira livre e no comércio informal da cidade de Currais Novos/RN, conforme legislação em vigor da Agência Nacional de Vigilância Sanitária ANVISA, e, dessa forma, verificar as condições sanitárias do produto em questão.

PALAVRAS-CHAVE: doce de leite, DVAs, enteropatógenos, alimentos artesanais.

\section{ANÁLISIS MICROBIOLÓGICO Y FÍSICO-QUÍMICA DEL DULCE DE LECHE VENDIDO EN EL COMERCIO INFORMAL DE CURRAIS NOVOS / RN}

\section{RESUMEN}

El dulce de leche es un alimento importante producido y vendido principalmente en Brasil y Argentina. Ese alimento tiene un alto valor nutricional y es menos perecedero que laleche y la aceptación es muy alta. (DEMIATE et al., 2001). Las DVAs (doenças veiculadas por alimentos) son actualmente responsables de la mayoría de los brotes de diarrea en casi todos los países. Los alimentos artesanales tienen más probabilidad que se presenten contaminados por el uso de materias primas no seguras (Duarte et al., 2005). ANVISA establece a través de la Resolución $\mathrm{N}^{\circ} 12$ de fecha 02 de enero 2001 que el dulce de leche debe ser analizado para detectar la presencia de los principales enteropatógenos (ANVISA, 2001). Este estudio tuvo como objetivo analizar las muestras microbiológicas del dulce de leche vendido en el comercio abierto e informal en la ciudad de Currais Novos/RN,conforme la legislación de la Agencia Nacional de Vigilancia Sanitaria - ANVISA y, así, verificar las condiciones sanitarias del producto en cuestión.

PALABRAS-LLAVE: Dulce de leche, DVAs, enteropatógenos, alimentos artesanales. 


\section{ANÁLISE MICROBIOLÓGICA E FÍSICO-QUÍMICA DE DOCE DE LEITE VENDIDO NO COMERCIO INFORMAL DE CURRAIS NOVOS/RN}

\section{INTRODUÇÃO}

O doce de leite é um importante alimento produzido e comercializado, principalmente, no Brasil e na Argentina (DEMIATE et al., 2001). Esse produto é resultante da cocção de leite com açúcar, podendo ser adicionadas outras substâncias alimentícias permitidas, até concentração conveniente à parcial caramelização (ANVISA, 1978). O doce de leite apresenta elevado valor nutricional por conter proteínas e minerais, além do conteúdo energético. É um alimento menos perecível que o leite e de grande aceitação sensorial (DEMIATE et al., 2001).

As doenças veiculadas por alimentos representam importante problema de saúde pública, pois se estima que milhões de pessoas de todo o mundo sejam acometidas por doenças transmitidas por alimentos, e a maioria está ligada às condições da matéria-prima, aos maus hábitos dos manipuladores (NOLLA; CANTOS, 2005). A ANVISA define como DVA: "Uma doença de natureza infecciosa ou tóxica causada pelo consumo de alimento ou água" (ZANDONADI et al., 2007).

As DVAs são responsáveis, atualmente, pela maior parte dos surtos de diarréia em quase todos os países. O desenvolvimento econômico e a globalização do mercado mundial, as alterações nos hábitos alimentares, com a crescente utilização de alimentos industrializados ou preparados fora de casa, alteraram o perfil epidemiológico dessas doenças, expondo a população a vários tipos de contaminantes (SCARCELI; PIATTI, 2002; CVE/CCD-SES, 2004). A comercialização de alimentos de origem animal em feiras livres, expostos em barracas sem refrigeração, sem proteção contra poeira e insetos, pode alterar sua qualidade (CORREIA; RONCADA, 1997).

Os alimentos artesanais têm possibilidade de se apresentarem contaminados pelo uso de matérias-primas de fontes não-seguras, utensílios mal higienizados ou contaminados, elaboração em condições impróprias e armazenamento e comercialização em temperatura inadequada, fatores que contribuem para aumentar o risco de causarem enfermidades (DUARTE et al., 2005). Do ponto de vista de saúde pública, a população deve ter ao seu alcance alimentos de boa qualidade, dentro de padrões pré-estabelecidos, não só em valores nutritivos, como também quanto às condições higiênicas que propiciam segurança para a saúde do consumidor (CORREIA; RONCADA, 1997; FAGUNDES; OLIVEIRA, 2004). A ANVISA estabelece por meio da Resolução RDC n ${ }^{\circ} 12$ de 02 de janeiro de 2001, que dispõe do regulamento técnico sobre padrões microbiológicos para alimentos, que o doce de leite deve ser analisado quanto à presença desses principais enteropatógenos: Salmonella sp., Coliformes a $45^{\circ} \mathrm{C}$ (Coliformes fecais) e Estafilococos coagulase positivo (Staphylococcus aureus) (ANVISA, 2001).

A Salmonella sp. é uma enterobactéria que pode causar graves infecções gastrintestinais de origem alimentar (ANTUNES PINTO, 1996). Staphylococcus sp. têm importância na epidemiologia das doenças veiculadas por alimentos, o que decorre de sua alta prevalência e do risco de produção, nos alimentos contaminados, de toxinas causadoras de gastrenterites alimentares (REIS et al., 2002).

Já os coliformes fecais, do ponto de vista sanitário, funcionam como indicadores capazes de evidenciar maior probabilidade de que o alimento tenha entrado em contato com material de origem fecal, indicando, com maior precisão, a possível presença de patógenos entéricos (NOVAK; ALMEIDA, 2002; LUND et al., 2007). 
O presente estudo teve por objetivo analisar, microbiologicamente, amostras de doce de leite comercializadas na feira livre e no comércio informal da cidade de Currais Novos/RN, conforme legislação em vigor da Agência Nacional de Vigilância Sanitária - ANVISA, e, dessa forma, verificar as condições sanitárias do produto em questão.

\section{MATERIAL E MÉTODOS}

\section{MATERIAL PARA ANÁLISE}

As amostras foram obtidas no comercio informal, acondicionadas em potes plásticos e conduzidas em temperatura ambiente para imediata análise. As amostras foram coletadas no início da manhã e pesavam aproximadamente 200 g. O transporte até o local de análise se deu nas mesmas condições de temperatura do local da coleta, e as análises microbiológicas foram iniciadas imediatamente após a obtenção das amostras.

\section{ANÁLISES FÍSICO-QUÍMICAS}

Foram realizadas análises físico-químicas: acidez titulável, $\mathrm{pH}$ e teor de gordura seguindo a metodologia preconizada por Brasil (2006). A determinação de sólidos solúveis foi realizada com emprego de refratômetro à temperatura de $25^{\circ} \mathrm{C}$, e o resultado foi expresso em ${ }^{\circ}$ Brix.

\section{ANÁLISES MICROBIOLÓGICAS}

No preparo das amostras utilizou-se alíquotas de $25 \mathrm{~g}$ de cada marca de doce de leite, estas foram pesadas assepticamente e homogeneizadas durante um minuto com $225 \mathrm{~mL}$ de água peptonada $0,1 \%$. Em seguida, a partir da diluição 10-1, foram preparadas em tubos contendo $9,0 \mathrm{~mL}$ de água peptonada $0,1 \%$.

Para a contagem de fungos e leveduras foi utilizada a técnica de pour plate, onde volumes de $0,1 \mathrm{~mL}$ e/ou 1,0 mL correspondente a cada diluição foram inoculados em placas de Petri estéreis e adicionado o meio ágar dextrose batata, resfriado e pH 3,5 acidificado com ácido tartárico $1,0 \%$. Após incubação a $37^{\circ} \mathrm{C}$ de cinco a sete dias foi efetuada a contagem das unidades formadoras de colônias (SILVA, JUNQUEIRA \& SILVEIRA, 1997).

Na contagem de coliformes a $37^{\circ} \mathrm{C}$ e a $45^{\circ} \mathrm{C}$ ou termotolerantes, a determinação foi feita pela Técnica de Tubos Múltiplos - NMP (número mais provável), na qual quantidades decrescentes da amostra (diluições decimais consecutivas) foram inoculadas em um meio de cultura adequado em uma série de três tubos, os quais fornecem resultados positivos ou negativos. A combinação desses resultados é usada na determinação do NMP. Este exame é feito através de duas etapas:

1 - Teste presuntivo: é a semeadura de volumes determinados da amostra, em tubos contendo caldo lauril sulfato triptose, que foram incubados a $35^{\circ} \mathrm{C} / 24$ a 48 horas. A formação de gás a partir da fermentação da lactose é prova presuntiva para a presença de bactérias do grupo coliformes. Neste teste foram semeados 36 tubos no total, englobando as quatro amostras.

2 - Teste confirmativo: será a transferência das culturas de todos os tubos positivos, para tubos contendo caldo lactosado verde brilhante bile, que foram incubados a $37^{\circ} \mathrm{C} / 24$ a 48 horas e para tubos contendo meio EC incubados durante 24 a 48 horas a $45^{\circ} \mathrm{C}$ em banhomaria com agitação. A produção de gás é prova confirmativa positiva. 


\section{RESULTADOS E DISCUSÃO}

\section{ANÁLISES FÍSICO-QUÍMICAS DOS DOCES}

As médias dos resultados obtidos nas análises dos doces (Tabela 1) encontram-se dentro dos padrões exigidos pela Portaria No 354, de 4 de setembro de 1997 (Brasil, 1997). A acidez titulável não diferiu significativamente entre os doces. $\mathrm{O}$ teor de gordura, a atividade de água e a textura também não diferiram estatisticamente.

Nas análises de $\mathrm{pH}$ houve diferença significativa entre os doces $\mathrm{C}$ e $\mathrm{D}$. O teor de sólidos solúveis no doce $\mathrm{E}$ apresentou $35^{\circ} \mathrm{Brix}$, maior que os demais (Tabela 1).

Tabela 1. Resultados das análises de cinco amostras de doces de leite do comércio informal da Cidade de Currais Novos/RN

\begin{tabular}{lcccc}
\hline Amostras & $\begin{array}{c}\text { Acidez titulável } \\
(\%)\end{array}$ & $\mathrm{pH}^{*}$ & $\begin{array}{c}\text { \% Gordura } \\
(\mathrm{m} / \mathrm{m})\end{array}$ & $\begin{array}{c}\text { Sólidos solúveis } \\
\text { ('Brix) }\end{array}$ \\
\hline $\mathrm{A}$ & 0,22 & 6,2 & 6,5 & 25 \\
$\mathrm{~B}$ & 0,23 & 6,4 & 9,5 & 24 \\
$\mathrm{C}$ & 0,26 & 5,2 & 8,3 & 26 \\
$\mathrm{D}$ & 0,23 & 6,6 & 8,1 & 23 \\
$\mathrm{E}$ & 0,28 & 6,3 & 9,5 & 35 \\
\hline
\end{tabular}

\section{ANÁLISES MICROBIOLÓGICAS DOS DOCES}

Os resultados das análises microbiológicas dos doces de leite, com e sem inspeção, estão resumidos na (Tabela 2). Das cinco amostras analisadas até o momento, apenas uma apresentou coliformes a 37 e a $45^{\circ} \mathrm{C}$ apresentou formação de gás nas $48 \mathrm{~h}$. Estes resultados estão de acordo com o recomendado pela Resolução nº12 (BRASIL, 2001).

Nas amostras analisadas verificou-se desenvolvimento de fungos e leveduras (Tabela 2).

Embora sua presença tenha sido constatada abaixo do limite, não significa que a mesma esteja isenta de toxinas, pois muitas micotoxinas podem permanecer viáveis até mesmo na ausência do fungo, sendo assim, não são facilmente degradáveis. Segundo Ferreira (2006), os valores de fungos e leveduras encontrados nas amostras D e E estão acima do limite máximo $\left(10^{3} \mathrm{ufc} / \mathrm{g}\right.$ ou $\left.\mathrm{mL}\right)$ aceitável. Portanto, estas amostras estão em condições higiênicas-sanitárias insatisfatórias, sendo assim, o produto está impróprio para o consumo por apresentar risco de presença de toxina que representa perigo severo à saúde do consumidor (Tabela 2).

Tabela 2. Resultados das análises microbiológicas de cinco amostras de doces de leite do comércio informal da Cidade de Currais Novos/RN

\begin{tabular}{|c|c|c|c|}
\hline Amostras & Coliformes a $37^{\circ}$ & ${ }^{*}$ Coliformes a $45^{\circ}$ & $\begin{array}{l}* * \text { Fungos e } \\
\text { Leveduras }\end{array}$ \\
\hline $\mathrm{A}$ & 42 & 62 & $2,3 \times 10^{3}$ \\
\hline B & 25 & 30 & $3,6 \times 10^{3}$ \\
\hline $\mathrm{C}$ & 47 & 42 & $2,4 \times 10^{3}$ \\
\hline $\mathrm{D}$ & 55 & 61 & $1,5 \times 10^{6}$ \\
\hline E & 38 & 48 & $1,9 \times 10^{6}$ \\
\hline
\end{tabular}

*Padrão: $5 \times 10$ NMP/g **Padrão: $10^{3}$ UFC/g (*BRASIL, 2001) 


\section{CONCLUSÃO}

Este tipo de estudo visa diagnosticar possíveis fatores de risco de doenças veiculadas por alimentos e que possam contribuir para a importância do controle higiênico sanitário além de alerta a população sobre medidas educativas a respeito e que possam esclarecer e orientar tais indivíduos como proceder para evitar que estas enfermidades ocorram.

Considerando a constante modificação econômica que vem ocorrendo no país, onde é possível perceber a intensa atividade informal dos cidadãos brasileiros, inclusive no que diz respeito aos serviços de alimentação prestados em locais públicos, como o comercio das feiras livres, é importante salientar que a questão da higiene alimentar, deve ser de interesse de todos, governo, profissionais de saúde, comerciantes e consumidores e que constitui indubitavelmente um grande desafio à Saúde Publica do país.

\section{REFERÊNCIAS}

ANTUNES PINTO, A. F. M. Doenças de origem microbiana transmitidas pelos alimentos. Millenium, v. 1, n. 4, p. 91-100, 1996.

ANVISA-Agência Nacional de Vigilância Sanitária Resolução RDC $\mathbf{n}^{\circ}$ 12, de 02 de janeiro de 2001 .

ANVISA-Agência Nacional de Vigilância Sanitária. Resolução CNNPA no 12, de 24 de julho de 1978.

BRASIL (2006) Instrução Normativa $\mathbf{N}^{\circ}$ 68, de 12 de dezembro de 2006. Oficializa os métodos analíticos oficiais físico-químicos, para controle de leite e produtos lácteos, em conformidade com o anexo desta Instrução Normativa, determinando que sejam utilizados nos Laboratórios Nacionais Agropecuários. Diário Oficial da União de 14/12/2006, Seção 1, Página 8.

CORREIA, M.; RONCADA, M. J. Características microscópicas de queijos prato, mussarela e mineiro comercializados em feiras livres da Cidade de São Paulo. Revista de Saúde Pública, v. 31, n. 3, p. 296-301, 1997.

CVE/CCD-SES-Centro de Vigilância Epidemiológica. Divisão de Doenças de Transmissão Hídrica e Alimentar. Toxinfecção alimetar por Salmonella em um evento científico. Revista de Saúde Pública, v. 39, n. 3, p. 515-518, 2004.

DEMIATE, I. M.; KONKEL, F. E.; PEDROSO, R. A. Quality evaluation of commercial samples of doce de leite - chemical composition. Ciência e Tecnologia de Alimentos, v. 21, n. 1, p. 1008-114, 2001

FAGUNDES, H.; OLIVEIRA, C. A. F. Staphylococcus aureus intramammary infections and its implications in public health. Ciência Rural, v. 34, n. 4, p. 1315-1320, 2004.

LUND, D. G.; ZAICOVSKI, C. D.; PRIETO, L. M.; CONCEIÇÃO, R. C. S.; ALEIXO, J. A. G.; ROMBALDI, C. V. Qualidade microbiana e aspecto visual de mandioca minimamente processada. Acta Scientiarum. Biological Sciences, v. 29, n. 2, p. 213-216, 2007. 
NOLlA, A. C.; CANTOS, G. A. Relationship between intestinal parasites in food handlers and epidemiological factors in the city of Florianópolis, Santa Catarina, Brazil. Cadernos de Saúde Pública, v. 21, n. 2, p. 641-645, 2005.

NOVAK, F. R.; ALMEIDA, J. A. G. Teste alternativo para detecção de coliformes em leite humano ordenhado. Jornal de Pediatria, v. 78, n. 3, p. 193-196, 2002.

REIS, R. B.; MAMIZUKA, E. M.; FRANCO, B. D. G. M. Standardization of an enzyme immunoassay for detection of Salmonella in foods. Ciência e Tecnologia de Alimentos, v. 22, n. 2, p. 105-110, 2002.

SCARCELLI, E.; PIATTI, R. M. Patógenos emergentes relacionados à contaminação de alimentos de origem animal. Biológico, v. 64, n. 2, p. 123-127, 2002.

SILVA, N.; JUNGUEIRA, V.C.A.; SILVEIRA, N.F.A. Manual de métodos de análises microbiológicas de alimentos. São Paulo: Varela, 1997.

SILVA, N.; JUNGUEIRA, V.C.A.; SILVEIRA, N.F.A. Manual de métodos de análises microbiológicas de alimentos. São Paulo : Varela, 1997.

ZANDONADI, R. P.; BOTELHO, R. B. A.; SÁVIO, K. E. O.; AKUTSU, R. C.; ARAÚJO, W. M. C. Atitudes de risco do consumidor em restaurantes de auto-serviço. Revista de Nutrição, v. 20, n. 1, p. 19-26, 2007. 